artigo

\title{
A moda argentina e a cultura popular
} Argentine fashion and popular culture

\section{[ LAURA NOVIK ]}

Argentina, reside no Chile. Diretora da Consultoria blink.d-sign, Inteligência de Consumo e Conteúdos de Moda. Atualmente desenvolve projetos de promoção da cultura do design na América Latina como co-diretora do Circuito Identidades Latinas e co-fundadora da ONG multinacional Raiz Design, a cargo dos projetos OBS América Latina / Observatório de Tendências Emergentes, Simpósio Raiz Design e Rede Ibero-Americana de investigação (ação em design ITACA). Colabora para revistas universitárias, livros e publicações de design, moda e da indústria têxtil na América Latina e USA. Docente universitária desde 1991 nas mais importantes faculdades de moda e design de Argentina, Chile, Colômbia, Uruguai e Espanha.

[resumo] A moda argentina é um fenômeno social, cultural e produtivo instalado no contexto urbano e integrado por diversas práticas que dão forma a uma totalidade que a essa altura se converteu numa das manifestações mais avançadas da indústria cultural argentina, em particular de Buenos Aires. 0 presente artigo apresenta uma visão sobre determinados eventos, práticas e contradições da moda no processo de busca de certas narrativas de identidade elaboradas sobre a cultura popular, o Outro e o exótico. A moda que este estudo retrata dá conta do impacto das formas propagadas nos centros internacionais da moda, mas também possiveis de ler como Buenos Aires/Interior, articulando diversos nexos entre centro/periferia, desde o periodo do Virreinato Del Rio de la Plata até as experiências após a crise de 2001.

\section{palavras-chave}

moda argentina; cultura popular; indústria cultural.

[abstract] Argentine fashion is a social, cultural and creative phenomenon set in an urban context and forged by a number of practices which shape a totality that has, by now, turned into one of the most forward expressions of the country's mass culture, particularly of Buenos Aires. This article looks on some of the events, practices, and contradictions of fashion and its process of establishing identity narratives generated by popular culture, and by the ideas of the Other and the foreigner. This study reflects on the impact of international fashion centers on the local culture - that may also be interpreted via a Buenos Aires-countryside standpoint - and articulates a number of links between downtown-outskirts, from the Virreinato Del Rio de la Plata period through the experiences of the post-2001 crisis.

[key words] Argentine fashion; popular culture; mass culture. 


\section{A visão feminina, a visão do Outro: mulheres européias}

Do mesmo modo que na música folclórica argentina, as típicas formações vocais de quartetos são herdeiras dos grupos vocais jazzísticos norte-americanos (as formações de tradição local são os duetos), como aponta Alabarces (s/d), a construção do imaginário da moda nacional se deve à visão européia, como uma forma pioneira de resgatar e valorizar aqueles elementos da cultura popular pouco visiveis para o ambiente local. Uma visão que demora um tempo para firmar-se, entretanto, durante a Belle Époque, começam a desembarcar em Buenos Aires costureiras européias experientes no negócio de alta-costura francesa. Vindas como representantes dos ateliês de estilistas, de tecidos e de aviamentos internacionais, sua futura atividade independente centralizou-se na cópia dos modelos das maisons e dos ateliês de moda consagrados no Velho Continente. Seu fino trabalho se concentrou numa importante clientela formada por muIheres da poderosa elite latifundiária da Argentina, que passavam grande parte do ano em Londres e Paris. Este fato impulsiona a proliferação de ateliês de nomes afrancesados como Henriette, Madame Suzane, Saint Felix, entre outros excelentes copiadores dos centros de moda, que se instalaram desde o início do século XX e desfrutaram suas décadas de glória até os anos 1950, alguns chegando a sobreviver inclusive até a década posterior (LESCANO, 2004).

Depois, com a eclosão da Segunda Guerra Mundial, se instalam os alicerces que permitiram a lenta edificação de uma moda local: por um lado, a forte expansão da indústria têxtil argentina e a raiz da substituição de importações (a Europa está consumida pela guerra e os Estados Unidos retaliavam o comércio com a Argentina por não tomar posição direta a favor do lado aliado); por outro, o processo de estruturação sindical do meio da costura a partir da fundação do Centro Argentino de Moda, em 1941, e a transformação da União Comercial de Alfaiates, iniciada em 1905 (CAROLA, 2005), na Câmara Argentina do Vestir (SAULQUIN, 2006). A socióloga Susana Saulquin observa que, entre 1930 e
1949, se desenvolve uma forte expansão das maisons de moda portenha, fato que estimulou o surgimento dos primeiros costureiros/criadores.

Neste contexto começa a se alinhar uma busca que incorpora ao design e à moda certos atributos de identidade provenientes da cultura pré-colombina ${ }^{2}$ e genuína criolla, dando forma a novas representações a partir da visão do Outro, o estrangeiro. Esta visão viaja por diferentes países da América Latina nas mãos de intelectuais, arquitetos e artistas refugiados das guerras mundiais durante a década de 1940. Alinhados ao pensamento e às estéticas da vanguarda moderna, se estabelecem principalmente em três destinos: México, Brasil e Argentina, de onde começam a identificar aquelas caracteristicas próprias que passam inadvertidas ou pouco valorizadas por parte do ambiente local. 0 historiador australiano Kevin Murray (2005) define 0 artesanato como a transformação de materiais comuns em objetos preciosos, caminho no qual se introduz a reflexão feminina, imbuída de espirito antropológico, à moda e ao design. Uma dessas mulheres é a cubana Clara Porset Dumas, formada na Universidade de Columbia, na Sorbonne e na Escola Nacional de Arquitetura em Paris, bem como no Black Mountain College, na Carolina do Norte, num curso liderado pelo bauhausiano Josef Albers (FLORES, 2001). A partir de 1936, estreita seus contatos com o México onde logo sente a influência da cultura artesanal e popular que culmina no lançamento, em 1952, da 1ª Exposição de Design Industrial e Artesanato Mexicano, denominada Arte en la vida cotidiana (FLORES, 2001). Lina Bo Bardi (1915-1992), imigrante italiana radicada no Brasil em 1945, onde inicia uma rentável atividade como designer e descobriu o valor das madeiras brasileiras para continuar numa investigação sobre a cultura popular (BORGES, 2007). Seu trabalho influenciou de maneira decisiva o movimento de design made in Brasil. $\mathrm{Na}$ Argentina surge a artista plástica e designer de moda Fridl Loos, graduada na Escola de Belas Artes de Viena e com experiência no mundo têxtil e no design de vestidos. Chega, no começo da década de 1940, em Buenos Aires, com seu marido, o arquiteto Walter Loos; juntos viajam ao noroeste argentino onde Fridl conheceu o mundo têxtil aimará, em Jujuy, e os ponchos dos gaúchos da província de Salta. Os resultados dessa descoberta de áreas têxteis, como os 
barracanes e ponchos, chegaram às lojas de Neiman Marcus em Nova York e vestiram as mulheres poderosas e intelectuais argentinas (VICTORIA, 2004).

Os desenhos de Fridl Loos difundiram a estética criolla em sofisticadas e vanguardistas linhas de roupa esporte e de noite, uma moda exótica com que Loos vestiu atrizes como a elegante Delia Garcés para quem criou um estilo particular (SCHOO, 2007). Sempre ligada aos círculos de artistas, em seu primeiro negócio em Viena contou entre seus clientes com Hedy Lamar e Lana Turner (VICTORIA, 2004). Foi figurinista em 11 filmes do cinema argentino, meio que a uniu a seus famosos clientes, as atrizes Amelia Bence, Marta de Oks, Lidia Satragno e Susana Rinaldi (LOOS, 2007). Mas também vestiu personagens poderosas como Amalia Lacroze de Fortabat e Helena Rubinstein, que era sócia capitalista do mais famoso empreendimento de Loos chamado Rancho (VICTORIA, 2004). A loja de moda batizada com o nome da moradia do gaúcho argentino segue o discurso baseado na representação das culturas originárias e criolla como o Outro exótico. Este refinamento dos elementos da cultura popular é parte de sua marca que o jornalista Juan Calcarami tenta traduzir desde as recordações de Niní Gomez, uma protagonista da sociedade portenha que, para sua crônica, recordou as épocas de passeios "num Pallard conversível cinza que o casal Loos tinha, sempre acompanhado de quatro galgos também cinzas" (CALCARAMI, 2007).

Fridl e Walter Loos pertenceram ao grupo de artistas e arquitetos da vanguarda argentina como Amancio e Delfina Williams, Tomás Maldonado, Horacio Baliero, Kurchan, Ferrari Ardeu, Bonet, Lidy Pratti, pioneiros da cena do moderno design argentino (LOOS, 2007). Fridl propôs uma moda alinhada dentro dos cânones do movimento moderno, é assim que seus desenhos chegaram ao público por meio da arquitetura de interior criada especialmente por seu marido Walter Loos (VICTORIA, 2004), como a loja da Avenida Santa Fé, com grandes vitrais sutilmente emoldurados, austeras vitrinas "decoradas com grandes punhados de milho ou simplesmente batatas" (CALCARAMI, 2007). Como seus companheiros Porset e Bo Bardi, Fridl Loos foi reconhecida de maneira tardia (possivelmente pelo fato de ser mulher e estrangeira $e_{\text {, ademais, }}$ por ter-se dedicado à moda).

\section{Outro do interior argentino}

Em meados dos anos 1960, outras apostas começam a questionar os símbolos da identidade, realizando uma moda com materiais e silhuetas provenientes da cultura local. Apelando ao uso de linguagem própria e com um público que inclui artistas e poderosos, mas que também atinge as classes médias intelectuais, a moda local começou a posicionar-se como fenômeno cultural aliado às artes plásticas de vanguarda. Nessa época surgem na cena internacional novos conceitos que reagem frente ao fenômeno da industrialização, como o movimento da L'Arte Povera na Europa, o "teatro pobre" do diretor polaco Jerzy Grotowsky que confronta o excesso com a austeridade (MURRAY, 2005), as estéticas e filosofias hippies e a moda étnica. São estímulos para o surgimento de discursos de moda próprios na América Latina, como ocorre com Zuzu Angel no Brasil, Marco Correa no Chile ou Paco Jamandreu na Argentina. Jamandreu, conhecido por ter vestido círculos de atrizes e Eva Perón, lança no final da década de 1960 seu look gaúcho, inspirado nos ponchos e silhuetas das vestimentas utilizadas pelos gaúchos da província de Salta. A partir de 1969, suas criações aparecem nas vitrinas da loja Saks de Nova York (VICTORIA, 2004) numa trajetória semelhante ao trabalho pioneiro de Fridl Loos realizado 30 anos antes.

Cabe mencionar o particular aparecimento de Mary Tapia, na mesma época, cujos trajes foram objeto de culto da geração de intelectuais e artistas progressistas ligados ao Instituto Di Tella ${ }^{3}$. 0 grupo, integrado entre outros por Dalila Puzzovio, Pablo Mesejian e Delia Candela, que se juntou a Rosa Bailon com sua mítica loja Madame Frou Frou na Galeria del Este, contribuiu com as correntes internacionalistas de vanguarda .

Este grupo apostou em atitudes inovadoras e cheias de provocação, avançadas para o seu tempo. Ao menos em suas intenções, absteve-se de opções políticas e ideológicas definidas, distanciando-se do status quo e do estilo de vida conservador, muito presente na ditadura ultracatólica do General Juan Carlos Ongania, que ocupou o poder entre 1966 e 1970 . Os 
ideais deste grupo foram compartilhados por uma geração de nível internacional que apoiava o movimento de direitos civis e a mobilização estudantil consolidada no Maio Francês. Grandes opositoras ao intervencionismo americano e a todo tipo de dependência, essas diversas frentes moldaram uma construção ideológica heterogênea que, na estética, inspirou a postura do "discurso local" promovido a partir das artes visuais, da música e, em especial, do nascimento do rock nacional e também da moda ${ }^{4}$. Nesta linha, Tapia entende a moda como fenômeno capaz de iluminar o caminho, difundindo um modo alternativo de conceber e criar com valores que avançaram contra os estilos conservadores da sociedade argentina e sua orgulhosa assimilação das estéticas irradiadas pelos centros de moda europeus. Para o lançamento de sua primeira e mais ovacionada coleção, Pachamama ${ }^{5}$ Prêt-à-Porter, Tapia expressou em um tom de protesto: "Em Buenos Aires a última moda não chega nunca, porque seis meses depois há que usar o mesmo que usam as européias. $E$, ao contrário, que bárbaro o que fazem nossas índias mestiças ou as mulheres do Paraguai, fenômeno indígena de Zulea, em barracanes, ponchos, tapeçarias e barrados bordados. Nesta coleção se misturam estas texturas com tecidos de Otavalo - cidade do Equador - e balletas ${ }^{6}$ feitos à mão no povoado de Cuenca, no Equador, ou centros de mesa de Quito. Por isso criar uma moda argentina se converteu em minha obsessão" (SOSA, 2006) .

Pela primeira vez no país, um criador de moda levanta sua voz interpretando um pensamento compartilhado com outras pessoas semelhantes da região, como o chileno Marco Correa, pioneiro da "moda latino-americana" ou "moda autônoma" que resgatou estéticas pré-colombinas e que argumentava em uma reportagem da revista de moda Eva: "Me agrada fazer moda diferente e lutar contra o complexo colonial que têm as chilenas" (SALINAS, 2007). Sua crítica é próxima à de Mary Tapia, que responde a uma sociedade entulhada pelos modelos europeus com a busca de novas opções nas raizes ancestrais.

Mas os gestos de Tapia indagam além do estabelecimento de uma "moda étnica", que hoje faz parte dos questionamentos como "fator local do design"8 ou as estratégias de moda com conteúdo de identidade. Seu trabalho se atreve a redefinir as classificações herméticas dos códigos do sistema industrial e a manifestar um verdadeiro tom irônico, que se encontrarão nas próximas gerações vindas da moda argentina.

A falta de preconceito de Mary Tapia e seu quase irônico sentido de elegância são notados também na música que acompanhou o desfile: rancheiras, camionetes e tangos muito velhos cantados por Mercedes Simone (FELISA PINTO citada por VICTORIA, 2004). Com estas estratégias, Mary Tapia pôs na cena portenha ${ }^{9}$ a voz de um interior totalmente desconhecido, longínquo, exótico e selvagem. A moda evidencia o impacto das correntes migratórias provocadas pela industrialização e modernização urbana do modelo econômico desenvolvido. A aparição dos provincianos na cena cultural portenha (como Mary Tapia e Felisa Pinto que são Tucumanas) permitiu a aparição não somente do imaginário estético, mas também a mesma forma corporal do interior, o que o psicólogo social e arquiteto Alfredo Moffat (1967) define como a cultura do cabecita negra ${ }^{10}$, convertendo estas apostas de moda num Outro exótico.

0 discurso estético de Tapia utiliza gestos lingüísticos que mesclam estéticas folclóricas e urbanas. Baseada no uso de materiais, texturas e cores pertencentes à cultura artesanal indígena ou criolla latino-americana em roupas de corte europeu ocidental clean. Trajes de alfaiate com texturas do noroeste argentino como os encontrados nos barracões, o picote (tecido de lã crua ou branca) e os aguayos (tecidos aimarás que as indigenas costumam usar para carregar seus filhos ou mercadorias). Forrerías (renda) em gaze hindu e laços de veludo junto ao ñandutí (renda) ou a chagua (tecido de fio vegetal), tecidos provenientes da região Chaqueña, território que atravessa de leste a oeste o norte argentino e que tem como países limítrofes Paraguai, Brasil e Bolívia. Por esta visão, a jornalista Felisa Pinto denomina o trabalho de Mary Tapia uma antropologia da moda (VICTORIA, 2004). Mas a maior singularidade de sua obra está em ter definido na cena portenha uma estética como forma de expressão ideológica, incorporando as representações do outro, difundindo 
sensações unidas à diversidade, espiritualidade e ecologia, além de posições políticas contrárias, mas estabelecidas desde 0 consumo. Uma atitude que compartilhou com outros designers de moda desses países, como a brasileira Zuzu Angel, cujo trabalho também utilizou temas do folclore, tecidos originais, cores tropicais e a fusão do puro e o sofisticado, somados a uma clara manifestação política ao produzir coleções convertidas em denúncias a respeito dos dramáticos e dolorosos efeitos da ditadura que arrebatou sua própria vida. Outro caso é o do chileno Juan Enrique Concha que liderou um movimento em prol do design têxtil nacional desde a fábrica têxtil Yarur, controlada pelo governo socialista de Allende. Sua coleção primavera-verão 1972/1973 foi colocada à venda com estampas de motivos da llha de Páscoa e do povoado de Diaquitas tentando responder a pergunta que ele mesmo propunha: "Por que pagar royalties no estrangeiro por padronagens de flores e desenhos abstratos que nada de significativo dizem a nós, os chilenos, se podemos explorar esta faixa riquíssima de desenhos originais?"11. Neste sentido, Tapia reconhece em entrevistas ${ }^{12}$ que a perspectiva de seu trabalho segue diferenciando-a das gerações atuais da moda argentina, que trabalham com muitos de seus critérios de design, mas sem a pretensão de constituir-se em estéticas com compromisso ideológico.

Ao final dos anos 1960, o golpe militar, liderado pelo general Onganía, levava ao fim um projeto de modernização capitalista, aliando as Forças Armadas aos grandes poderes econômicos do país, o que aumentou a tensão social, política e cultural, provocando múltiplas fraturas e lutas em diversas frentes, incluindo a moda. A socióloga Susana Saulquin destaca que os círculos criativos do Di Tella e Galeria del Este refletiram, em nível local, as estéticas e estilos de vida germinados em Carnaby Street e Portobello Road (SAULQUIN, 2006), motivo pelo qual alguns círculos de artistas e designers foram tachados de forasteiros por outros grupos mais radicais. Estas acusações também chegaram ao rock nacional, desacreditado por setores da música popular, como o tango e o folclore, por tocar uma música estrangeira, acusado pelos mais reacionários que os tachavam de putos e comunistas (em alusão ao espírito libertário pregado pelo movimento, as relacionam os cabelos longos e estilos de roupas coloridos), mas ademais criticado por setores juvenis intelectuais de esquerda que entendiam o rock como "um invento imperialista para manter a juventude dormindo, e para provar isto não vacilavam em impulsionar o argumento de "drogados" também sustentado pelos setores reacionários que deviam combater" (MARCHI, 2005, p. 38). Do mesmo modo, enquanto a direita tachava Di Tella de comunista e inclusive de subversivo, a esquerda o criticava por suas filiações estéticas de rumo internacional. Em resposta ao trabalho dos artistas aliados ao status institucional, como o Instituto Di Tella ou o Museu de Bellas Artes, um grupo de artistas lança a exibição da chamada "Tucumán Arde", na Confederación General Del Trabajo (GCT), uma resposta ao programa governamental de industrialização do investimento americano conhecido como "Operativo Tucumán".

Em 24 de março de 1976 começou o autodenominado "Proceso de Reorganización Nacional" com a participação das três forças armadas sob o comando de uma Junta Militar que derrubou o governo de María Estela Martínez de Perón. Os terrorismos do Estado, aliados a métodos repressivos e sangrentos, foram criados para anular a guerrilha e toda participação do povo. Logo intelectuais, sindicalistas, estudantes, docentes e profissionais foram perseguidos, assassinados, "desaparecidos", enquanto muitos cidadãos se exilavam no exterior ou no interior da Argentina ${ }^{13}$. Neste período a artista têxtil e designer de Catamarca Manuela Rasjido assistia seu curso de Filosofia e Letras na Universidade de Tucumán e iniciava, em 1978, seus primeiros trabalhos no âmbito têxtil com uma atitude solitária, quase de recolhimento, numa dança existencial com a qual, consciente ou inconscientemente, marcava um dos períodos mais sangrentos da história nacional. Sua casa e estúdio "La Soledad" está encravado no lugar que a viu nascer e onde se criou, 0 pequeno povoado de Santa María, localizado no coração dos Valles Calchaquíes e palco histórico no qual se desenvolveram manufaturas têxteis desde as épocas da colônia ${ }^{14}$. Ela e seu companheiro, o reconhecido artista plástico argentino Enrique Salvatierra, vivem e trabalham conscien- 
tes de que pisam um solo extraordinário, "rodeado de impressões do passado entre arqueologia, mitos e lendas"15, como diz Salvatierra. Para Rasjido, cujas primeiras investigações indagaram nas brilhantes e coloridas tinturas andinas, seu povo é todo um cenário natural que a inspira oferecendo-Ihe ao longo do dia gamas de cores e luzes mutantes. Cedo a designer estendeu sua indagação às técnicas de fiação e tecido ancestrais, para finalmente experimentar com as iconografias da cultura pré-colombina que deram origem a um estilo que define como "arte para usar". Seus vestidos de linhas abstratas transformam o papel utilitário da roupa numa experiência estética, num caminho próximo aos vestidos como meio de expressão que Sonia Delaunay lançou na década de 1920 (INSTITUTO DE LA INDUMENTÁRIA DE KIOTO, 2005). A obra de Rasjido é o perfeito contra-ataque à cultura do consumo de bens importados dos EUA, do Oriente e da Europa, estimulada pelas políticas econômicas da ditadura militar. 0 silêncio e a solidão portam uma poderosa mensagem que Manuela explica: "Ainda sendo consciente de estar nadando contra a corrente, eu escolhi mergulhar em meu interior e no interior de meu país"16.

\section{O Outro marginado}

Se no final dos anos 1960 a expressão de uma moda local fazia referência à cultura popular ao Outro do interior argentino, em fins da década de 1980 aparece uma plêiade de "outros", os que permaneceram ocultos ou calados em épocas da ditadura. A moda argentina desta etapa, convertida num dos braços do movimento underground, torna-se visivel a partir de novas aparências estéticas nas quais se destacam os esquisitos penteados novos ${ }^{17}$. Denominados com 0 mote de "modernos", se projetaram com força na cena social a partir da Primeira Bienal de Arte Jovem (1988), espaço que, de acordo com o sociólogo Mario Margulis (MARGULIS, 2005), reuniu artistas e intelectuais menores de 30 anos facilitando seu encontro.

Desse modo, firma-se uma das correntes sobressalentes da chamada "movimentação portenha", eleita pelos meios como referência estética da transgres- são desde fins dos anos 1980 e durante a década seguinte. Sergio De Loof surge como cabeça visivel de um grupo mais extenso. Em junho de 1989, seu primeiro show chamou-se "Latina Winter by Cottolengo Fashion", com roupas velhas provenientes da instituição beneficente Dom Orione. Denominados "gênios pobres" (SAULQUIN, 2006), Gabriel Grippo, Andrés Bañ, Gaby Bunader e Kelo Romero lançaram a "Moda da Pobreza" através de propostas que exploraram na estética do Outro (pobres, travestis, bolivianos, desocupados, etc.), tratados com um tom irônico e frívolo, na mesma linha que propõe De Loof para definir seu estilo: "Eu sou muito, muito, muito local. Não tenho tradução. Sou uma mistura: escorregadio, profundo, frívolo..." (SCHEJTMAN, 2006).

0 "boro look" (que se refere tanto à mendicância como ao desleixo) inspira uma narrativa da pobreza que já tinha surgido em 1982 pelas mãos dos japoneses Yohi Yamamoto e Rei Kawakubo. Estes criadores projetaram, utilizando farrapos, tecidos esburacados e sem costura, o cânone de beleza nipônico: "formosura da pobreza consciente" (INSTITUTO DE LA INDUMENTÁRIA DE KIOTO, 2005, p. 635). Sua obra, situada no patamar da moda de alta classe, rompe em partes desconstrutivistas os códigos indumentários clássicos, indagando nos limites corporais mediante deformações da silhueta e dos volumes. Uma estética que repercutiu no imaginário dos designers portenhos da cena underground.

A desenfreada expressão com o que estas apostas vieram à luz desde as catacumbas da fase ditatorial, caminhando pela impressão de uma crise econômica cada vez mais evidente, as propostas fizeram emergir temáticas incômodas da cena urbana (o ser sudaca ${ }^{18}$, a desocupação, o conservadorismo). Uma das figuras mais interessantes que se inscreve nestas buscas é Kelo Romero (1962-2006). Como De Loof e Grippo, sua obra se concentrou numa espécie de alquimia de ninharias e residuos (tecidos econômicos, roupas vendidas por quilo), convertidas em peças valiosas a partir de novos conceitos como a coleção "Sudaca Fashion" em que acerta sua visão crítica em formas desconstrutivistas para a estética denim.

Dez anos depois da primeira Bienal de Arte Jovem e com uma nova e mais violenta crise institucional, econômica e social como back stage, Sergio De Loof apresentou um desfile na Galeria de Arte 
de Ruth Benzacar, fazendo brilhar seus modelos com roupa velha, deteriorada e descosturada. "Eu vejo o fashion na favela"19. Sempre tive uma coisa pop e sempre meio boliviano"20. Esta visão que navega entre a frivolidade e o resgate amoroso das estéticas da pobreza logo é atingida pela realidade no cenário pós-menemismo, caracterizado por uma profunda e estendida crise nas instituições, na economia e na sociedade civil, onde florescem fenômenos esquecidos como a pobreza, a precariedade do interior e os novos mendigos da antiga classe média: os catadores de lixo que invadem Buenos Aires.

E depois da crise de 2001, estratégias de marketing se constituem em herdeiras das atitudes provocadoras e transgressoras propostas pelos gênios "pobres". É o caso da marca de moda A.Y. Not Dead, cujo berço foi a mesma crise de 2001. Seu nome joga com a semântica em tom irônico, aludindo à sensação de pertencer aos sobreviventes da crise, flerta com o imaginário do rock, muito popular na cultura juvenil argentina, com a frase "Punk not dead", zomba das formas coloquiais populares que deformam a pronúncia do inglês (I'm como A.Y.), além disso, interpreta as siglas de um nome conhecido por seus vínculos com a corrupção durante o governo do ex-presidente Menem, Alfredo Yabrán (A.Y.), sobre quem ainda pesam dúvidas sobre sua morte (Alfredo Yabrán Not Dead).

A marca, convertida em fetiche pelos fashionistas jovens, recomendada em blogs por personagens da mídia e visitantes estrangeiros, lança propostas desejadas pela juventude revelando um tom da cultura local e popular que foi se amassando ao longo das sucessivas crises: a cultura do rock bairrista ou rock chabón (palavra com a qual nos bairros populares portenhos se designa os jovens), a cultura das torcidas delinqüentes do futebol e a cultura da cumbia bailantera (uma música baseada nos sons da cumbia tradicional, mas em forma simplista e dançante). Esta transformação da cultura popular, que para alguns é resultado do processo de empobrecimento das classes médias argentinas, que teve início com o golpe militar de 1976 e vai até a crise de 2001 (MARCHI, 2005), inspira inovadoras estratégias de marketing de moda. $A$ marca A.Y. Not Dead usou como espaço para a comunicação de sua identidade os palcos da cultura popular urbana: promoções espalhadas nos transportes coletivos portenhos, com uma passarela que teve como palco o campo do popular time de futebol Boca Juniors, cenografias de passarela com estéticas dançantes ${ }^{21}$, até um vernissage na calçada de sua loja onde serviram pão com chouriço ${ }^{22}$ e cerveja (SCHEJTMAN, 2006).

\section{Crise de identidade}

Fridl Loos morre antes de lançar sua mostra no Centro Cultural Recoleta de Buenos Aires em julho/agosto de 2000, momento em que sua visão pioneira é resgatada pelos meios da moda nacional. Nesse mesmo ano, dois grandes prêmios nacionais se concentram em Manuela Rasjido, designer de moda e artista têxtil de Catamarca: o Prêmio da Fundação Konex e o Prêmio Designer de 2000 do Governo da Cidade de Buenos Aires. No ano seguinte, o reconhecimento chega à obra de Mary Tapia, 40 anos depois do lançamento de suas propostas de uma moda com marca de identidade local. Recebe a Tijera de Oro - Tesoura de Ouro, máxima distinção da Câmara Argentina de Moda -; La Tijera de Plata - Tesoura de Prata - por sua trajetória; o Prêmio Criador Argentina da Sociedade Científica Argentina; e o Prêmio Konex de Platina 2002, que premia a trajetória dos mestres consagrados. Estes prêmios são indícios da valorização da identidade como motor de busca e ao mesmo tempo da herança recortadas nas manufaturas têxteis artesanais surgidas nos ateliês semi-industriais e dentro dos lares do interior do país nas épocas da colônia ${ }^{23}$.

No mesmo ano 2002, o mais reconhecido dos autores do design argentino, Pablo Ramírez, apresentou na passarela do Buenos Aires Fashion sua coleção Pátria. Uma homenagem aos caudilhos responsáveis por heróicos gestos libertários. A coleção Pátria para o inverno 2002 reelaborou os casacos clássicos masculinos de 1800, completando os conjuntos com gorros frígios arrematados com emblemas bordados com cristais Swarovski. A visão de Ramírez foi romântica, emocionante e poderosa por seu refúgio na memória que elegia os heróis da libertação sul-americana como San Martín e Bolivar. A platéia ovacionou de pé o jovem mestre cultor de Balenciaga, que trouxe épocas gloriosas e valores perdidos aprendidos à base de protestos escolares e ilustrações coloridas 
da revista infantil Billiken ${ }^{24}$.

Os anos posteriores ao período neoliberal impulsionados pelos dois governos sucessivos de Carlos Menem, passadas as épocas que promoveram o consumo em massa de bens importados e que possibilitaram aos argentinos o contato com muita oferta particular do primeiro mundo, facilitando a apropriação coletiva das linguagens internacionais, o imaginário da cultura popular local reaparece com novas formas. Neste processo se lança a mostra Identidad Criolla, do ciclo MALBA MODA 2006 no Museu de Arte Latino-Americano. A exposição está montada sobre uma retrospectiva de Mary Tapia, um vídeo que joga com imagens de Manuela Rasjido, bem como com as propostas da faixa de designers incluídos no chama- do "design de autor" (VICTORIA, 2004), dentre os quais figuram Marcelo Senra, da província de Salta, criador de estilos internacionais realizados em tecidos do noroeste argentino; Araceli Pourcel e seu trabalho sutil em torno das roupas e tecidos latino-americanos; e até o consagrado, criativo e empreendedor Martín Churba que, com sua equipe de design de Tramando, busca em silhuetas, texturas e cores a diversidade cultural de um país no que se inclui ao povo boliviano ${ }^{25}$.

Passada a crise aguda, a moda argentina continua em seu processo de busca dos arredios sinais de uma identidade tão enraizada que não perde a forma, que não solta os laços de um passado criollo heróico, da mão do imaginário pré-colombina e buscando gestos da cultura popular urbana, num giro às vezes incitado desde a política, mas, sobretudo, como expressão de uma necessidade coletiva de valorização do próprio tanto a força dominante capaz de ejetar o imaginário nacional para fora do abismo.

\section{NOTAS}

\footnotetext{
[1] Tradução Graziella Cabral.
}

\section{${ }^{[2]} \mathrm{NT}$ : periodo anterior às viagens e descobertas de Cristovão Colombo.}

${ }^{[3]} 0$ Instituto Di Tella foi criado em junho de 1958 e foi o epicentro da cultura dos anos 1960 e referência das manifestações de vanguarda que aconteceram. Seu suporte foi a Fundación Torcuato Di Tella, cujo diretor, Jorge Romero Brest (1905-1989), foi um dos homens mais importantes da arte, e foi quem liderou os rumos do centro experimental e vanguardista, emblema naquela década. Para saber mais, acesse:

<http://www.utdt.edu/ver_contenido.php?id_contenido=1454Ctid_item_menu=3065>

${ }^{[4]}$ Pablo Alabarces faz referência ao ano de 1965 quando o músico Litto Nebia, à frente da banda de rock Los Gatos Salvajes grava seu primeiro long-play com temas próprios em castelhano. Em 1967, à frente de uma nova formação, "Los Gatos", aparece na cena com os temas La balsa e Ayer no más que alcançam uma audiência massiva, introduzindo o conceito de rock nacional.

${ }^{[5]}$ Em Aymara, Pacha significa tempo ou universo e mama significa mãe. Na mitologia inca, Pachamama representa a deusa da fertilidade, ainda hoje reverenciada como símbolo da Mãe Terra.

${ }^{[6]} \mathrm{NT}$ : na Espanha, balleta é pano de cozinha, trapo ou algo semelhante.

[7] 0 artigo de Cecilia Sosa, "Nobleza gaucha," está disponivel em:

<http://www.pagina12.com.ar/diario/suplementos/radar/9-3468-2006-12-21.html>

${ }^{[8]}$ Jorge Montana realizou trabalho utilizando o conceito Factor Local e foi o ganhador do Premio Casa Mueso del Objeto Brasileiro na área de ensaios.

[9] Os termos portenhos usados neste texto fazem referencia aos habitantes de Buenos Aires. No Chile, portenhos são os habitantes de Valparaiso, cidade portuária, como Buenos Aires.

${ }^{[10]}$ Cabecita negra é um termo desrespeitoso e racista, utilizado pelas classes médias e altas

argentinas (em especial de Buenos Aires), para se referir às pessoas com traços indígenas (pele escura e cabelos negros) provenientes das zonas rurais do interior argentino e pertencentes às classes populares.

${ }^{[11]}$ As iniciativas em torno da moda latino-americana no Chile referem-se ao artigo da jornalista Rosario Mena, "Historia del vestuario femenino en Chile. Años 70's Raíces Propias". Disponível em: <http://www.nuestro.cl/notas/rescate/moda9.htm> Acesso em: 15 set. 2007.

${ }^{[12]}$ Tapia expõe esta idéia na entrevista "Vestidos con historia". Disponivel em: $<$ http://www.revistanueva.com.ar/nota.php?numero=00813\&tnoticia=2> Acesso em: 15 set. 2007.

[13] Para maiores informações, ver Carlos A. Floria y César A. García Belsunce, "Historia de la Argentina contemporánea, 1880-1983". Buenos Aires: Alianza, 1989

${ }^{[14]}$ Entrevista da autora com Manuela Rasjido para este artigo.

[15] Texto enviado por Enrique Salvatierra para realização do presente trabalho.

${ }^{[16]}$ Resumo extraído do texto do escrito de Manuela Rasjido.

${ }^{[17]}$ Este título é de uma canção do músico de rock Charly García que faz referência à moda dos "modernos".

[18] Sudaca é um termo pejorativo utilizado na Espanha para se referir aos latino-americanos que chegam em busca de melhores oportunidades de trabalho. 
[19] Villas Miseria ou Villas de Emergencia é o nome dado às favelas na Argentina.

${ }^{[20]} 0$ grupo boliviano integra os imigrantes das zonas urbanas na Argentina. Habitualmente, realizam atividades nos setores da construção, da confecção têxtil e na venda de verduras e frutas em feiras.

${ }^{[21]}$ Gênero de música popular na Argentina inspirado na música tropical latino-americana como a cumbia. Para Sergio Marchi (2005), surgiu no auge do governo de Menem e representa para as classes médias a música melancólica latina sempre ignorada pelas classes média e alta argentinas.

[22] Plural da palavra choripán, um tipo de embutido do tradicional assado criollo que mistura as palavras chouriço e pão.

${ }^{[23]}$ Durante o Virreinato del Río de la Plata, mercado comum colonial, com Buenos Aires como centro portuário, diversas cidades provedoras como Catamarca, Salta, Corrientes, Santiago del Estero, Tucumán o Córdoba (e também do Alto Perú e Bolivia) desenvolveram suas manufaturas texteis em fibras de lã, algodão seda e cânhamo, provocando um grande desenvolvimento destas regiões, que declina com a aparição do Regulamento do Livre Comércio Regulamento de 1778 - e posteriormente a criação da Aduana. Para mais informações sobre este tema, veja Hernán Asdrúbal Silva, "El comercio entre España y el Río de la Plata (1778-1810)". Banco de España - a Servicio de Estudios de Historia Económica, nº $26-1993$.

[24] Revista Billiken foi uma publicação da Editora Atlántida dirigida ao público escolar. Além de "historinhas", desenhos e jogos, tinha sessões de história, geografia, biologia, etc. Sua linha editorial tinha forte conteúdo nacionalista.

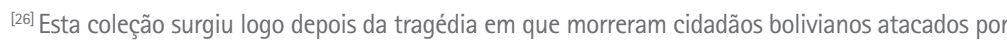
Ihamas em uma oficina clandestina de Buenos Aires.

\section{REFERÊNCIAS}

ALABARCES, Pablo Alabarces. Entre gatos y violadores. Buenos Aires: Ediciones Colihue, s/d.

BELLOC, Bárbara. Tribus porteñas. Conejillos de indias y blancos ratones - un brevario de zoología urbana. Buenos Aires: Libros, 1998.

CALCARAMI, Juan. "Recobrando refinamiento". Revista de Artes Visuales, Buenos Aires, 2000. Disponivel: < http://www.ramona.org.ar/files/r04.pdf > Acesso em: 24 set. de 2007.

CAROLA, Sainz Carola. "Una fiesta, Los cien años de la Cámara Argentina de la Moda". Diario Clarín, Suplemento Mujer, 07/06/2005, Buenos Aires, Argentina.

CRÓNICA de Adelia Borges. Disponivel em: <http://www.mre.gov.br> Acesso em: 21 set. 2007

FLORES, Oscar Salinas; PORSET, Clara. Una Vida inquieta, Una obra sin igual. México: Universidad Nacional Autónoma de México, Facultad de Arquitectura, 2001.

GIUNTA, Andrea. Vanguardia, internacionalismo y política. Buenos Aires: Paidós, 2001.

INSTITUTO DE LA INDUMENTÁRIA DE KIOTO. Moda, una historia desde el Siglo XVII al Siglo XX - a colección del Instituto de la Indumentaria de Kioto. Taschen do Brasil: 2005.

LOOS, Fridl. El fallecimiento - La Nación. Disponível em:

<http://www.ayudatareas.com.ar/noticias2/4/archivo-c448.shtml> Acesso em: 12 dez. 2007.

MARCHI, Sergio. El rock perdido - de los hippies a la cultura chabona, Le Monde Diplomatique, El Diploó. Buenos Aires: Capital Intelectual, 2005.

MARGULIS, Mario et. al. La cultura de la noche - la vida nocturna de los jóvenes de Buenos Aires. Buenos Aires: Biblos, 2005.

MOFFAT, Alfredo. Estrategias para sobrevivir en Buenos Aires. Buenos Aires: Editorial Jorge Alvarez, 1967.

MURRAY, Kevin. Craft unbound - make the common precious. Australia: Thames and Hudson, 2005.

SALINAS, Juan Luis. "Marco Correa - el hombre que revolucionó la moda chilena". Revista Ya, Diario El Mercurio, Chile, 6 de novembro de 2007.

SANTOS, Lidia. Tropical Kitsch - mass media in latinamerican art and literature. Markus Wiener, 2006.

SAULQUIN, Susana. Historia de la Moda Argentina, del Miriñaque al diseño de autor. Argentina: Emecé Editores, 2006.

SCHEJTMAN, Natali. Argentina está de moda. Disponível em: <http://www.pagina12.com.ar/diario/ suplementos/radar/9-2923-2006-04-09.html> Acesso em: 12 out. 2007.

SCHOO, Ernesto. Delia Garcés, la eterna ninfa. Disponivel em:

$<$ http://www.lanacion.com.ar/archivo/Nota.asp?nota_id=747578> Acesso em: 15 out. 2007.

VICTORIA, Lescano. Followers of Fashion Falso - dicccionario de la moda. Buenos Aires, Interzona Ed, 2004. 